\title{
International Adoption Comparative Legal Research - Child Adoption in Georgia, Issues for Legislative Harmonization
}

\author{
Nino Mindiashvili, PhD student \\ Grigol Robakidze University, Tbilisi, Georgia
}

Doi: 10.19044/esj.2018.v14n5p173 URL:http://dx.doi.org/10.19044/esj.2018.v14n5p173

\begin{abstract}
International Adoption is a subsidiary measure for the protection of children - it only becomes an option if reintegrating a child into his/her extended family or adoption in the child's country of origin is not possible. What are the rules that must be followed in intercountry adoption cases? What are each participant's rights and duties? Who is allowed to adopt a child? What is the procedure? What are the opportunities and the risks if you become involved in providing a child with a proper home for the first time? This article aims to answer these questions and many others. It is intended as a source of ideas for professionals or authority involved in adoption.
\end{abstract}

Keywords: Adoption, child rights, divorce, marriage, international adoption, children's welfare

- Introduction

Throughout the poorer countries of the world, millions of children live out their young lives in substandard institutions or in the streets. Thousands of couples in the more advantaged countries of the West have demonstrated their eagerness to offer permanent homes to many of these children through adoption and have been doing so for more than decades.

The World Population Plan of Action adopted in 1974 at the World Population Conference called for facilitating child adoption so that involuntarily sterile and sub-fecund couples could achieve their desired family size. Implicit in this recommendation was the idea that adoption is a means to approximate biological parenthood for couples who would otherwise be unable to have children. More than three decades later, the general view is that, in societies where marriage is being increasingly delayed, childbearing is postponed and levels of biological childlessness are on the rise, increasing numbers of persons are resorting to alternative means of experiencing parenthood, including through adoption. This report analyses adoption trends 
in light of changes inutility and childbearing in order to assess the extent to which the generalized view presented above holds true.

Aim of this article is to visualize the problems of adoption process and provide some practical recommendations for international and local child adoption, I do believe that child is the most valuable asset of society and its harmonized growing and socialization into our community is the most favorite task not only for authorities, but also for humanity as well.

\section{- Problems of adoption, overview}

The problems that should be seen as central to the international adoption debate are the misery and deprivation that characterize the lives of huge numbers of the children of the world. Millions of children die regularly of malnutrition and of diseases that should not kill. Millions more live in miserably inadequate institutions or on the streets. (Board., 1986) Their situations vary: some institutions are worse than others are; some "street children" maintain a connection with a family while others are entirely on their own. But there can be no doubt that overwhelming numbers of children in the poor countries of the world are living and dying in conditions which involve extreme degrees of deprivation, neglect, exploitation, and abuse. (UNICEF., 1989) International adoption should be seen as an opportunity to solve some of these real and desperate problems for some children. It should be structured to maximize this positive potential by facilitating the placement of children in need of nurturing homes with people in a position to provide those homes.

International adoption can, of course, play only a very limited role in addressing the problems that the children of the world face. Solutions lie in reallocating social and economic resources both among countries and within countries, so that more children can be cared for by their birth families. However, given the fact that social reordering on a major scale is not on the immediate horizon, international adoption clearly can serve the interests of at least those children in need of homes for whom adoptive parents can be found.

Some have suggested that international adoption programs might conflict with programs designed to improve the lives of the millions of children now in need or with efforts to accomplish the kind of social reordering that might help the children of the future. For example, some argue that instead of promoting and pursuing adoption, governments and individuals in the welloff, industrialized countries should devote increased resources to more costeffective programs designed to promote the well-being of children in their native lands. These efforts could include improving foster care arrangements, sponsoring orphanages, and supporting various UNICEF projects. Such efforts, however, are not inconsistent with supporting foreign adoption. Indeed, the opposite is true. Foreign adoption programs are likely to increase awareness in the United States and other receiving countries of the problems 
of children in the sending countries. These programs give those who adopt reason to identify, through their children, with the situations of other children not lucky enough to have found homes. Foreign adoption is thus likely to help create a climate more sympathetic to wide-ranging forms of support for children abroad.

Another argument voiced against international adoption is that it might relieve pressure within some sending countries to deal with social problems that need attention. Nevertheless, this argument also collapses upon analysis. Sending children abroad for adoption tends to highlight rather than to hide the fact that there are problems at home. Indeed, it seems likely that a major reason for the hostility exhibited by many sending countries toward foreign adoption relates to their governments' embarrassment at having domestic problems spotlighted by this public confession of their inability to take care of their own children.

Although speculative arguments can always be mounted, it is unlikely that adoption of a relatively small number of the world's homeless children will significantly interfere with the efforts to assist those other children who remain in their native countries. Indeed, the nations of the world are in general agreement that "the best interests of the child" should be the paramount principle governing the placement of children outside their biological families. (U.N., 2007) Given the real problems confronting the world's children, it should be clear that this principle requires laws and policies designed to facilitate the international placement of children in need of homes.

Care should be taken, of course, to prevent international adoption from creating new problems. Adoption must not be used to break up viable birth families, and those who want to adopt must not be allowed to use their financial advantage to induce impoverished birthparents to surrender their children. There is a need for laws that prohibit baby buying, and for rules governing the process by which a child is removed from one parent to be given to another. The rules should ensure that the birthparents have voluntarily surrendered or abandoned their child, or have had their parental rights terminated for good reason. There is also a need for rules designed to ensure that adoptees receive loving, nurturing adoptive homes, and are protected against any form of exploitation. However, it is patently absurd to talk as if the real dangers for children were the dangers that they might be taken from their birthparents for purposes of abuse and exploitation. Nonetheless, public discourse about international adoption focuses overwhelmingly on its alleged risks. Concern is regularly expressed in this country and abroad about the dangers that children will be kidnapped or bought from their birthparents for sale to rich North Americans; the media in this country give headline coverage to stories of kidnapping rings" or "baby trafficking." There are, of course, some documented instances of kidnappings and of improper payments to 
birthparents. There is no evidence that these practices are widespread, and it is quite unlikely that they are. (Lucker-Bubel, 1990) Current law makes it extremely risky for adoption in term diaries and would-be adopters to engage in baby buying or kidnapping. Even if some might be willing to engage in such activities if this were the only way or the easiest way to accomplish an adoption, the fact is that it is not. The world is, sadly, all too full of birthparents desperate to find homes for the children they cannot care for, and of children who have already been surrendered or abandoned. When one looks beneath the surface of most media and other stories of "child trafficking," it becomes clear that the term "trafficking" is used very loosely. The stories sometimes

Critics of international adoption often voice concern that children will not receive appropriate care in their new families and countries. Arguments which could protect that position that it is unfair to separate children from their racial, ethnic, cultural, and national groups of origin. Loss of the group link and sense of group heritage is said to be a deprivation in itself. Moreover, growing up in a foreign land is said to pose risks of discrimination.

Those who voice these concerns again ignore the realities of children's current situations. International adoption represents an extraordinarily positive option for the homeless children of the world, compared to all other realistic options. Most of these children will not be adopted otherwise. They will continue to live in inadequate institutions or on the streets. Foster care is available only to a limited degree and sometimes results in little more than indentured servitude. The homeless children who survive to grow up often will face virulent forms of discrimination in their own country, based on their racial or ethnic status, or simply on the fact that they are illegitimate or orphaned.

The research studies on the outcome of international adoption show that these children and their families function well and compare favorably on various measures of emotional adjustment with other adoptive families, as well as with biological families. (Tizard, 2006) (Linowitz, 1988)

This is strikingly positive evidence since most international adoptees have had problematic pre-adoptive histories, which could be expected to cause difficulties in adjustment. (medical care of children , 2009)

The studies show that adoption has, for the most part, been very successful in enabling even those children who have suffered extremely severe forms of deprivation and abuse in their early lives to recover and flourish. Some of the research hints at the complex issues involved in being part of a biracial, bicultural, binational family.

Studies provide no evidence that the challenge of establishing a satisfactory ethnic and cultural identity causes any harm to the international adoptee. The findings are consistent with those in the transracial adoption studies. Black children who grow up in white families emerge with a strong 
sense of black identity. At the same time, they tend to have a bicultural or multicultural orientation.

They apparently enjoy an unusual degree of comfort in both black and white worlds, and are unusually committed to a future life in which they can relate to both those worlds. They are flourishing in all the terms in which psychic health and social adjustment are typically measured. There is no evidence that a multicultural identity is problematic from the perspective of the children involved. There has been no focus in the studies on determining what special positives might be inherent in international adoption for the children, their adoptive families, or the larger society. However, some studies hint at the rich quality of the experience involved in being part of an international adoptive family and the special perspective its members may develop on issues of community. (Rorbech, 1991) It seems clear that the debate over international adoption has little to do with genuine concerns over risks to children. Children are being sacrificed to notions of group pride and honor. As Tizard has described: It is argued that the practice is a new form of colonialism, with wealthy Westerners robbing poor countries of their children, and thus their resources. National pride is involved. However poor the country, they find the implication that they cannot care for their own children to be undignified and unacceptable. Thus poor countries feel pressure to hold on to what they term "their precious resources," and rich countries feel embarrassed to do anything that looks like colonialist exploitation. But there is no real conflict between the interests of the sending and those of the receiving nations. International adoption serves a symbolic function for those in power. Sending countries can talk of their homeless children as "precious resources," but it is clear that the last thing these countries actually need is more children to care for. At the same time, the well-off countries of the world have no burning need for these children. Their governments might be willing to permit the entry of adoptees from abroad to enable those struggling with infertility to parent, but international adoption is not seen as serving any strong national interest. So the homeless children end up as "resources" that the receiving countries of the world are quite willing to forgo to improve relations abroad.

The starting point should be agreement that children are not to be thought of as "resources," belonging in some fundamental way to their racial, ethnic, or national communities of origin. The world should take seriously the sentiments enunciated in international human rights documents that children are entitled to a loving, nurturing environment, and that their best interests should be the guiding principle in the structuring of international adoption. Receiving countries need to take action to build trust. They must recognize that there are genuine concerns about exploitation, as well as a long history of resentment. Good faith could be demonstrated and children's interests served through offers to develop and fund programs to benefit children's welfare 
within a sending country, in conjunction with any international adoption programs that are instituted. Mechanisms could be developed to provide sending countries with regular feedback on what has happened to the children sent abroad for adoption. Regular reports could help assure sending countries that their children are receiving good treatment and are thriving in their new adoptive homes. Sending and receiving countries need to agree on a legal framework for international adoption (Carlson, 1988 ) that would facilitate placement.

The model should be one in which each of the key decisions in the adoptive countries, which provide examples of how the laws of two nations can be coordinated to facilitate the adoption process (Bartholet, 1993). Receiving countries should revise their adoption, immigration, and nationalization laws to remove impediments to international adoption, and to ensure fully protected status to all foreign adoptees.

\section{- Recommendations}

For Georgian legislation on adoption better development Georgia has to focus on following issues:

Georgia has to development of agreements with other nations on a legal framework facilitating international adoption. This could be done either under the auspices of a new Hague Convention or apart from it.

Developing local legislation Georgian government has to recognize in such agreements of the principle that children's best interests require that children in need of homes has to be placed for adoption as expeditiously as possible. Children deserve nurturing homes now and not simply at some distant point in the future. Delay hurts and may do permanent injury

Elimination of the immigration law provisions that now restrict the children available for adoption by Georgia's citizens to those satisfying the narrow "orphan" definition. Qualification for entry into the Georgia of all children that appropriate sending country authorities designate as being available for adoptive placement.

Revision of Georgia legislation to ensure that foreign agency decisions releasing children for adoption and foreign adoption decrees are honored by Georgia agencies and courts. This would help ensure fully protected adoptive status to children adopted from abroad and would eliminate the necessity for duplicative adoption proceedings

Create centralized social service network of adoption of Georgia

Georgian authorities Also have to harmonize and ensure that child's rights will be guaranteed and socialization will be in accordance with international conventions requirements Georgian legislation has to develop and adopt practice which is tested by most of European countries and considers following: 


\section{STEP 1direct contact}

You have taken the first step in the adoption process and contact directly to "center of adoption". After a few general questions, you may be referred to a local department of social services or a to a private child placing agency for orientation.

\section{2 step orientation}

Family must be invited to a meeting to learn more about the types of children waiting for adoptive families and about the adoption process. This may be a group meeting with other families who are interested in adoption or may be an individual meeting with the agency adoption worker. Feel free to ask questions. This is a time for you to get some of your questions answered.

\section{Step 3 training}

A training curriculum which consists of 48 to 60 hours of instruction is required of every individual interested in becoming an adoptive parent. Several consecutive weeks of training must be offered with adoption workers and trained foster/adoptive parents as instructors. Panels of former foster children, adoptive and/or foster parents provide additional insight of parenting

Children from the foster care system. In addition, other specialists such as therapists, mental and physical heath clinicians, etc. offer information during the training.

\section{Step 4 application/eligibility}

Some agencies will offer the application at the beginning of the training and others will offer it at the end of the training. Application forms vary from agency to agency. Do not be put off by the personal questions on the application. Complete it, sign it, and return it to the agency.

The adoption worker will explain during the home study how the information you provided will help to determine the kind of child that will fit best in your family.

\section{Step 5 home study}

During the home study, you will talk about your reasons for wanting to adopt and the type of child your family can best parent. The adoption worker will talk about adoptive parenting, including parenting children with special needs. All members of your family including your adult children will be involved. The home study will be completed through a series of meetingsindividual or group. At the conclusion of the home study, your family and the adoption worker will decide whether you are ready to adopt and what type of child you can best parent.

\section{Step 6 selection}

The adoption worker will show you pictures of available children and tell you about each child. There are also listings of waiting children available on. When you find a child you are interested in, together, you and the child's agency will consider whether your family may be right for this child. Deciding 
against adopting a particular child will not prevent you from being considered for other children.

\section{Step 7 placement}

The placement process starts with visits between the child and the family. The number of visits before actual placement depends on the child's comfort in being able to move into a new situation. When the adoption worker feels that the child is ready to move and that the family is ready to receive the child, arrangements are made for placement in the adoptive home.

\section{Step 8 Observation}

After the child is placed in your home, the adoption worker will visit. The visits are to help you and the child adjust to this new situation. It helps you to assume your new role as parents. This is the time to talk with the worker about any concerns, you may have. Initial adjustment concerns are to be expected. Talk about them early on; waiting too long may cause problems later. Law must require the child to live in your home a minimum of 6 months and be visited at least 3 times or more before the adoption can be finalized.

\section{Step 9 legal procedures and finalization}

To finalize the adoption, it is best to get an attorney. The attorney will file a petition for adoption with the court. The court will request a report from the agency. The agency submits the report and the judge enters the final order of adoption.

\section{- Conclusion}

The current tendency to glorify group identity and to emphasize the importance of ethnic and cultural roots combines with nationalism to make international adoption newly suspect in this country as well as in the world at large. Restricting international adoption does not put poor countries in a better economic position or a better power position with respect to foreign governments. It is simply a symbolic gesture "for" the nation and "against" the

Foreigners that is easy and cheap to make. The children themselves have no political influence, and their voices are not heard. The nations of the world should move beyond political hostilities and symbolic acts to focus on the real needs of children. If they did, they would accept international adoption as a good solution for at least some portion of the world's homeless children and could begin to restructure their laws and policies to facilitate rather than impede such adoption. One side benefit would be that many more of the infertile who want to parent would be given the opportunity to do so through adoption. These people now feel under significant pressure to pursue biological parenthood through high-tech infertility treatment or complicated surrogacy arrangements - pressure that makes little sense in a world suffering 
in myriad ways from overpopulation. Another side benefit would be enrichment of our understanding of the meaning of family and of community.

\section{References:}

1. Bartholet, E. (1993). Adoption and the politics of parenting. New York: Houghton Mifflin.

2. Board., U. E. (1986). Exploitation of working children and street children. . U.N. Doc. E ICEF/1986/CRP.3, .

3. Carlson, R. (1988). Transnational adoption of children. . Tulsa Law Journal, 23:317, 366-70.

4. Linowitz, J. B. (1988). Unaccompanied children (New York: 1988), . New York : (New York: journal.

5. Lucker-Bubel. ( 1990). Inter-country adoption and trafficking in children: An initial assessment of the adequacy of the international protection of children and their rights, . Geneva: D.C.I. .

6. medical care of children . (2009). "remarkably well”, 747-51.

7. Rorbech. (1991). Are those kids yours? American families with children adopted from other countries. New York,: Hague Report,.

8. Tizard, B. (2006). Intercountry adoption: A review of the evidence. Journal of Child Psychology and Psychiatry, 743-56.

9. U.N. (2007). Adoption Declaration Article 5 ("In all matters relating to the placement of a child outside the care of the child's own parents, the best interests of the child, particularly his or her need for affection and right to security and continuing care, s. U.N.

10. UNICEF. ( 1989). Summary, The state of the world's children. New York. New York: UNICEF House.

\section{Additional Sources}

\section{International sources}

11. Adoptive Families. (n.d.). Cost of adoption update: 2012-2013. Retrieved http://www.adoptivefamilies.com/articles/585/domestic-internationalfoster-adoptionexpenses-2012-2013

12. Adoption Board (2004) Corporate Plan 2004-2007. Dublin: The Stationary Office Ames, E. (1997)The developmental outcomes of Romanian orphanage children adopted to Canada. Final Report to Human Resources Development, Canada.

13. Bartholet, E. Family bonds: Adoption and the politics of parenting. New York: Houghton Mifflin, 1993.

14. Bagley, C. with Young, L. \& Scully, A.(1993) International and Transracial Adoptions Aldershot: Avebury.

15. Bowlby, J. (1969) Attachment and Loss London: Hogarth. 
16. Brodzinsky, D.M. (2006) Openness Questionnaire for Adolescents. Unpublished Manuscript.

17. Child Welfare Information Gateway. (2012). Finding and using postadoption services. Retrieved from https://www.childwelfare.gov/pubs/f_postadoptbulletin

18. Dalen, M. (2001) The State of Knowledge of Foreign Adoptions http://www.comeunity.com/adoption/adopt/research3.html

19. Department of Health and Children, Guide for Practitioners, Standardized Framework for Intercountry Adoption Assessment, compiled by Gill Haworth and John Simmonds, (undated)

20. Martin, M., Carr, A., Burke, L., Carroll, L. \& Byrne, S. (2006) The Clonmel Project. Mental Health Service Needs of Children and Adolescents in the South East of Ireland: A Preliminary Screening Study, Clonmel: Health Service Executive.

21. Levin, A. R., Zeanah, C. H., Jr., Fox, N. A., Nelson, C. A. (2014). Motor outcomes in children exposed to early psychosocial deprivation. Journal of Pediatrics, 164, 123-129.

22. Pinderhughes, E., Matthews, J., Deoudes, G., \& Pertman, A. (2013). A changing world: Shaping best practices through understanding of the new realities of intercountry adoption. Retrieved from http://adoptioninstitute.org/publications/a-changing-worldshapingbest-practices-through-understanding-of-thenew-realities-ofintercountry-adoption/

23. U.S. Department of Health and Human Services, Administration for Children and Families. (2014). Re-homing of adopted children: responsibilities for states and opportunities in the provision of postadoption services (ACYF-CB-IM-14-02). Retrieved from http://www.acf.hhs.gov/sites/default/files/cb/im1402.pdf

24. Georgian sources

25. http://ssa.gov.ge/index.php?sec_id=498\&lang_id=GEO

26. The Law of Georgia on Adoption and Fostering Upbringing)

27. Law of Georgia "Social Aid"

28. https://www.allnews.ge/sazogadoeba/148243-

$\% \mathrm{E} 1 \% 83 \% \mathrm{~A} 0 \% \mathrm{E} 1 \% 83 \% 9 \mathrm{D} \% \mathrm{E} 1 \% 83 \% 92 \% \mathrm{E} 1 \% 83 \% 9 \mathrm{D} \% \mathrm{E} 1 \% 83 \%$ A0\%E1\%83\%98\%E1\%83\%90-

$\% \mathrm{E} 1 \% 83 \% \mathrm{~A} 8 \% \mathrm{E} 1 \% 83 \% 95 \% \mathrm{E} 1 \% 83 \% 98 \% \mathrm{E} 1 \% 83 \% 9 \mathrm{~A} \% \mathrm{E} 1 \% 83 \% 9$ $0 \% \mathrm{E} 1 \% 83 \% 93-$

$\%$ E1\%83\%90\%E1\%83\%A7\%E1\%83\%95\%E1\%83\%90\%E1\%83\%9 $\mathrm{C} \% \mathrm{E} 1 \% 83 \% 98 \% \mathrm{E} 1 \% 83 \% \mathrm{~A} 1-$

$\%$ E1\%83\%9E\%E1\%83\%A0\%E1\%83\%9D\%E1\%83\%AA\%E1\%83 \%94\%E1\%83\%93\%E1\%83\%A3\%E1\%83\%A0\%E1\%83\%94\%E1\%8 $3 \% 91 \% \mathrm{E} 1 \% 83 \% 98$ 
\%E1\%83\%A1\%E1\%83\%90\%E1\%83\%A5\%E1\%83\%90\%E1\%83\% A0\%E1\%83\%97\%E1\%83\%95\%E1\%83\%94\%E1\%83\%9A\%E1\%83 \%9D\%E1\%83\%A8\%E1\%83\%98.html 